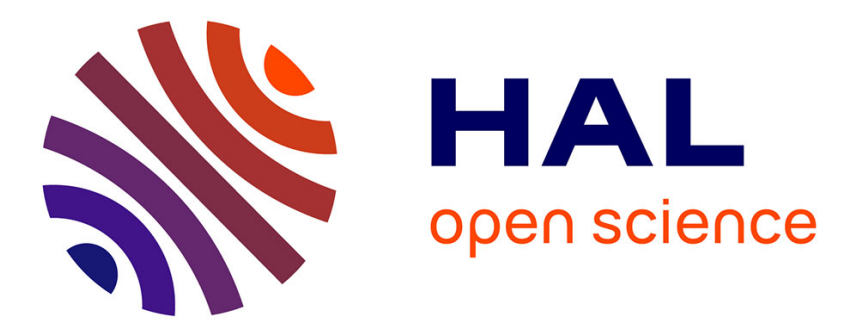

\title{
Challenges and issues facing lithium metal for solid-state rechargeable batteries
}

\author{
A. Mauger, M. Armand, C.M. Julien, K. Zaghib
}

\section{To cite this version:}

A. Mauger, M. Armand, C.M. Julien, K. Zaghib. Challenges and issues facing lithium metal for solid-state rechargeable batteries. Journal of Power Sources, 2017, 353, pp.333 - 342. 10.1016/j.jpowsour.2017.04.018 . hal-01510632

\section{HAL Id: hal-01510632 \\ https://hal.sorbonne-universite.fr/hal-01510632}

Submitted on 19 Apr 2017

HAL is a multi-disciplinary open access archive for the deposit and dissemination of scientific research documents, whether they are published or not. The documents may come from teaching and research institutions in France or abroad, or from public or private research centers.
L'archive ouverte pluridisciplinaire HAL, est destinée au dépôt et à la diffusion de documents scientifiques de niveau recherche, publiés ou non, émanant des établissements d'enseignement et de recherche français ou étrangers, des laboratoires publics ou privés. 


\title{
Challenges and issues facing lithium metal for solid-state rechargeable
}

\section{batteries}

\author{
A. Mauger ${ }^{1}$, M. Armand ${ }^{2}$, C. M. Julien ${ }^{3, *}$, K. Zaghib ${ }^{4, *}$ \\ ${ }^{1}$ Sorbonne Universités, UPMC Paris 06, IMPMC -Institut de Minéralogie, de Physique des \\ Matériaux, et de Cosmochimie, 4 place Jussieu, F-75005, Paris, France \\ ${ }^{2}$ CIC Energigune, Parque Tecnologico de Alava, Albert Einstein 48, Ed. CIC, 01510 Miñano, \\ Spain \\ ${ }^{3}$ Sorbonne Universités, UPMC Paris 06, PHENIX-Physicochimie des Electrolytes et \\ Nanosystèmes Interfaciaux, UMR 8234, 4 place Jussieu, F-75005, Paris, France \\ ${ }^{4}$ Institut de Recherche d'Hydro-Québec (IREQ), 1800 Bd Lionel-Boulet, Varennes, Quebec \\ J3X 1S1 Canada
}

\begin{abstract}
The commercial use of lithium metal batteries was delayed because of dendrite formation on the surface of the lithium electrode, and the difficulty finding a suitable electrolyte that has both the mechanical strength and ionic conductivity required for solid electrolytes. Recently, strategies have developed to overcome these difficulties, so that these batteries are currently an option for different applications, including electric cars. In this work, we review these strategies, and discuss the different routes that are promising for progress in the near future.
\end{abstract}




\section{Introduction}

Following the suggestion by Armand et al. [1] to use solid polymer electrolytes, many researchers have followed this strategy to develop lithium-metal batteries. The first attempts to commercialize $\mathrm{Li}$ solid polymer electrolyte batteries were not successful because of the $\mathrm{Li}$ dendrites that formed at the surface of the $\mathrm{Li}$-metal $\left(\mathrm{Li}^{0}\right)$ electrode. The dendrites resulted in short-circuits or breaks to form micron-sized aggregates, with battery fires occurring in some instances. In retrospect, the problems in the case of the AIEA (UK) [2] project can be traced to the use of $\mathrm{PEO}-\mathrm{LiCF}_{3} \mathrm{SO}_{3}$, electrolyte, where the presence of the non-conductive crystalline $\mathrm{P}\left(\mathrm{EO}_{3}-\mathrm{LiCF}_{3} \mathrm{SO}_{3}\right)$ phase made the conduction path very inhomogeneous. The choice of membranes ( $\sim 8$ microns thick) in the project led by AVESTOR resulted in short circuits because of issues with handling the material. The problem may have been aggravated by the choice of $\mathrm{LiV}_{3} \mathrm{O}_{8}$, which was partially soluble, and resulted in passivation deposits on the Li metal. Thus, the development of Li-metal batteries was delayed due to safety issues. Then the 1990s saw the exponential development of Li-ion batteries, in which the negative electrode was graphitic carbon that avoids the dendrite problem. The current density is limited to avoid a "traffic jam" of $\mathrm{Li}^{+}$ ions at the entrance between the graphite planes, (i.e. plating of $\mathrm{Li}^{0}$ instead of intercalation, a dangerous situation with a liquid electrolyte), but the system is adequate for many applications. Since then, much progress has been made to advance the Li-ion battery (LiB) industry. Some problems encountered with $\mathrm{LiBs}$ still limit their use today. The graphite negative electrode is of course heavier than lithium for a given capacity, even if the latter is used in excess. Besides, a copper current collector must be used as it is one of the few metals that does not form an alloy with lithium, but this is a weight (and sustainability) penalty. On the other hand, with Li-metal electrodes, the excess Li can serve as its own current collector. It is difficult to simultaneously 
optimize for high energy density and high power density. For instance, the combination $\mathrm{LiFePO}_{4}-$ $\mathrm{Li}_{4} \mathrm{Ti}_{5} \mathrm{O}_{12} \mathrm{LiBs}$ are safe and have high power density that compares with that of supercapacitors. However, their energy density is low $\sim 70 \mathrm{Wh} \mathrm{kg}^{-1}[3,4]$, compared to the graphite/high voltage layered oxide battery $\left(180 \mathrm{Wh} \mathrm{kg}^{-1}\right)$, which has lower power density and reduced safety. The LiBs and their applications are discussed in a recent book [5], and recent reviews are dedicated to them [6-9]. It was thought that it is nearly impossible to avoid the dendrite formation at the interface between lithium metal and liquid electrolytes, unless the charge rate was low, limiting the use of Li-metal electrodes to primary devices. However, Aurbach et al. [10] showed that the use of gel or all-solid polymer electrolyte solves the problem of dendrite formation at applicable charge rates. Strategies were developed to suppress Li dendritic growth by the use of gel-polymer electrolytes, increased ionic conductivity, and the choice of the appropriate counter-electrode. The lithium-metal polymer cell (LPC) with a $\mathrm{LiFePO}_{4}$ counter-electrode now provides a combination of high power - high density with long cycle life and safety [11] that is attractive for use in electric cars that were commercialized by the Bollore group in the framework of the Autolib' car-sharing program. In addition, LPCs are all solid-state batteries, a clear advantage for portable use, and the rate of self-discharge is an order of magnitude lower than that of LiBs. These properties justify the renewed interest in the LPCs to which the present review is devoted.

We did not discuss two chemistries that are at the level of fundamental research: Li-S and Li-air batteries for different reasons. Any report on the current works on Li-S batteries would imply a length that exceeds the limit, and we decided to write a separate review devoted to this subject. In the $\mathrm{Li}$-air case, one has to go from $\mathrm{O}_{2}$ to $\left[\mathrm{O}_{2}\right]^{\circ-}$ superoxide anion, to ${ }^{-} \mathrm{O}-\mathrm{O}^{-}$peroxide to form $\mathrm{Li}_{2} \mathrm{O}_{2}$. The peroxide oxidizes to form oxygen during recharge. Problem is that $\left[\mathrm{O}_{2}\right]^{--}$is a powerful nucleophile, and $\mathrm{O}_{2}{ }^{2-}$ is a powerful base. The oxidation of $\mathrm{O}_{2}{ }^{2-}$ gives birth to a fraction of singlet $\mathrm{O}_{2}$ that is a powerful oxidizer. As a consequence, no solvent can resist, and all the 
results that are published since decades seem to confirm it.

\section{The surface of metallic lithium}

Many results have been published on the formation and propagation of dendrites, recently reviewed in Ref. [12]. In a recent work [13], ions are randomly distributed in a simulated region in which they move according to Brownian motion. An active region and/or active sites at which deposits occur with a given probability reflects a compromise between the rate of the electrochemical reaction and the Brownian motion. This model was used to suppress the formation of dendrites at the surface of the Li electrode with the help of pulse charging [13]. The location of preferential dendrite growth at the late stage of formation is the tips of the protrusions [12]. The dendrite protrusions are mitigated by optimization of all the parameters at the solidelectrolyte interface (SEI).

The difficulty in the preparation of the metallic lithium surface, free of any defect, leads to the formation of a dendrite or granular morphology on the surface upon cycling. Different strategies were followed to overcome this problem.

\subsection{Increase the effective surface area}

Better plating/stripping efficiencies and homogeneity are observed when the current density is low [14]. To comply with this constraint, efforts were made to increase the effective surface area so that the same power density is achieved with a lower current density. Li metal powders were considered [15-17], but the preparation of such powders is expensive and handling hazardous. 

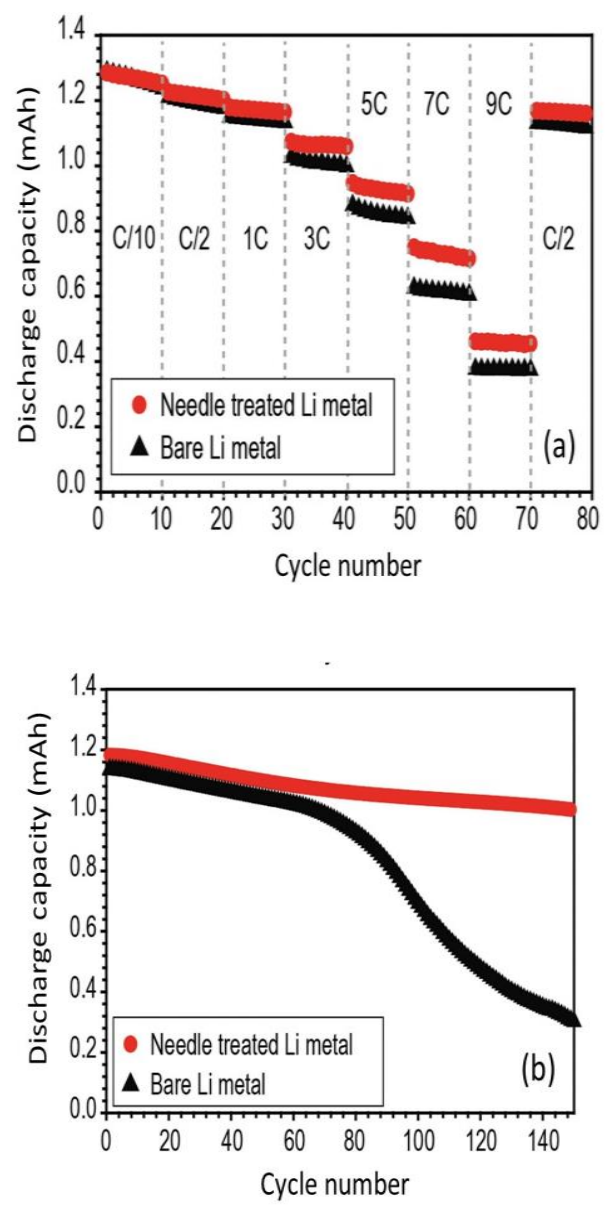

Figure 1. Electrochemical measurements of $\mathrm{Li} / \mathrm{LiFePO}_{4}$ half-cells employing $\mathrm{Li}$ metal with and without micro-needle surface treatment. (a) A comparison of the discharge capacities of the cells at different discharge rates with the charge rate constant at $\mathrm{C} / 2\left(0.53 \mathrm{~mA} \mathrm{~cm}{ }^{-2}\right)$. (b) The cycling performance was measured at $\mathrm{C} / 2$ rate $\left(0.53 \mathrm{~mA} \mathrm{~cm}{ }^{-2}\right)$ between 2.0 and $4.2 \mathrm{~V}\left(\mathrm{vs} \mathrm{Li}^{+} / \mathrm{Li}^{0}\right)$. The electrolyte is a mixture of ethylene carbonate/diethyl carbonate (EC:DEC $=1: 1$ by volume) containing $1 \mathrm{~mol} \mathrm{dm}{ }^{-3} \mathrm{LiPF}_{6}$. [18]. (Reproduced with permission from ACS Publications).

Another strategy is to modify the surface structure by a micro-needle technique [18]. A microneedle roller made from polylactide produced 340 micro-needle patterns at the surface during only one rotation of the roller head. The impedance of the Li metal and the overpotential of 
$\mathrm{LiFePO}_{4} / \mathrm{Li}$-metal cells were significantly reduced by the micro-needle-treatment, due to the increased effective area. The electrochemical signature is reported in Fig. 1. A liquid electrolyte was used, since this work was focused on the properties of the lithium surface. The measurements on a cell with a polymer electrolyte have not been reported as far as we know.

\subsection{Optimize the mechanical properties at the Li-electrolyte interface}

The electrolyte shear modulus should be above $6 \mathrm{GPa}$ to inhibit dendrite formation. Acrosslinked polymer electrolyte with $10^{5} \mathrm{~Pa}$ can cycle a lithium anode for long-term without shortcircuit [19]. An alternative is to apply internal mechanical pressure to the cell, in which case the growth of the dendrites is inhibited. The beneficial effect of pressure was reported for a lithiummetal/polymer cell with $\mathrm{LiFePO}_{4}$ and $\mathrm{Li}_{1.2} \mathrm{~V}_{3} \mathrm{O}_{5}$ electrodes [11].

\subsection{Protection of the lithium surface}

Efforts were directed to protect the lithium surface with an artificial solid-electrolyte interface by coating with an organic material [20]. Ryou et al. treated a polyolefin separator with a polydopamine coating $[20,21]$. The resultant catechol-mediated adhesion between the separator and lithium surface was strong and not only insured uniform $\mathrm{Li}^{+}$flux, but also relieved the mechanical strain built-up during electrochemical deposition/stripping of metallic lithium.

A successful approach proposed by Ding et al. [22] utilizes $\mathrm{Cs}^{+}$or $\mathrm{Rb}^{+}$salts at the additive level; these ions in concentration $<0.1 \mathrm{~mol} \mathrm{dm}^{-3}$ have effective reduction potentials lower than that of $\mathrm{Li}^{+}$. Consequently, any dendrite that begins to grow attracts these additive ions due to the higher current density in its vicinity. The accumulation of $\mathrm{Cs}^{+}$or $\mathrm{Rb}^{+}$ions generates an electric field that repels incoming $\mathrm{Li}^{+}$ions, forcing them to move to adjacent regions and undergo deposition. The net result is a leveling of the metallic lithium surface (see Figure 2). The test that 
was done on a $\mathrm{Li} / 1 \mathrm{~mol} \mathrm{dm}^{-3} \mathrm{LiPF}_{6}$ in $\mathrm{PC}$ with $0.05 \mathrm{~mol} \mathrm{dm}^{-3} \mathrm{CsPF}_{6} / \mathrm{Li}_{4} \mathrm{Ti}_{5} \mathrm{O}_{12}$ cell confirmed the absence of dendrites. Moreover, the dendrites that were initially formed gradually disappeared in the presence of the additive ions. Although the safety margin is low because the difference in reduction potential between $\mathrm{Li}^{+}$and the additive ions is small, this is a promising approach.

Another approach to address the formation of dendrites on the lithium metal surface is to apply an interlayer between the lithium and the electrolyte [23]. This interlayer must be both strong and flexible to accommodate the change in volume of the lithium electrode during cycling. A monolayer of amorphous and hollow carbon nanospheres meets these requirements, enabling reversible cycling of the lithium metal at a current density $1.0 \mathrm{~mA} \mathrm{~cm}{ }^{-2}$ for 150 cycles and a coulombic efficiency of $99 \%$. This successful result is due to the fact that the carbon in the interlayer is not a good electrical conductor, otherwise the lithium would deposit on the surface of the interlayer rather than on the lithium metal surface. These different innovative approaches resulted in major improvements that are promising routes to solve the problem with dendrite on the lithium-metal surface. 


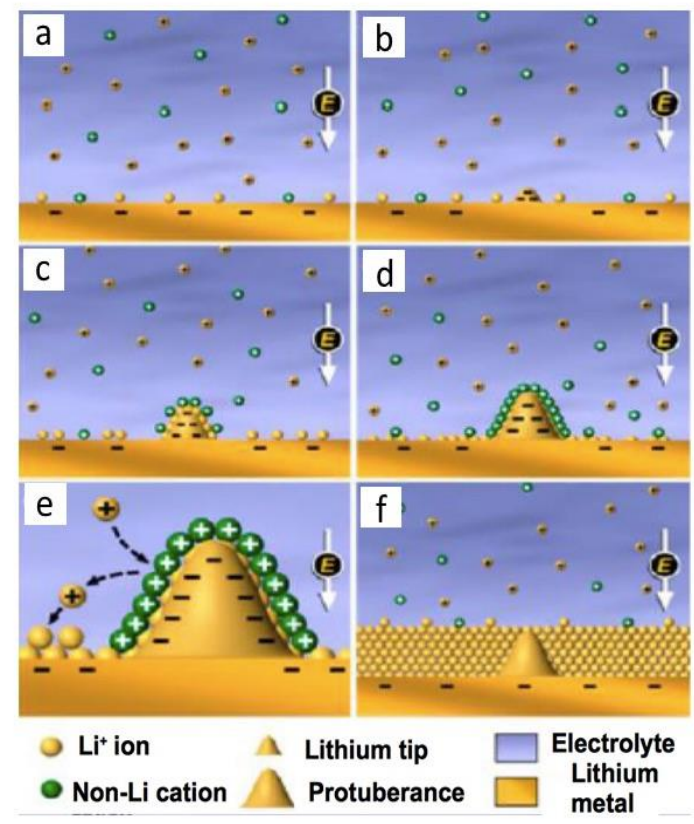

Figure 2. Self-Healing Electrostatic Shield (SHES) mechanism at sequential steps [24]. (a): First, both $\left(\mathrm{Li}^{+}\right)$and the cations $\left(M^{+}\right)$are adsorbed on the Li surface under an applied voltage $(\mathrm{Va})$ slightly lower than the Li reduction potential but higher than the additive reduction potential. (b): Li forms protuberant tips. $\left(M^{+}\right)$with a reduction potential lower than $V a$ (c) will not electroplate on the tip. Instead, they will accumulate in the vicinity of the tip to form an electrostatic shield (d), which will repel incoming $\mathrm{Li}^{+}$ions, forcing further $\mathrm{Li}^{+}$deposition to adjacent regions of the anode (e) until a smooth deposition layer is formed (f). (Reproduced with permission from Elsevier).

\section{The electrolyte}

The electrolyte solvents strongly affect the safety and stability of the battery; consequently efforts are underway to obtain solvent-free solid polymer electrolytes (SPE) that offer the strong mechanical strength that liquid electrolytes lack. However, the ionic conductivity of SPEs is low. In contrast, SPEs have suitable mechanical properties, and liquid electrolytes possess suitable 
ionic transport properties. Recent studies have focused on gel polymers electrolytes (GPE) that combine both the appropriate mechanical and ionic transport properties by using additives in the polymer. The formation of nanocomposites to enhance the mechanical properties is not new and has been used in other fields such as supercapacitors and others. For instance, we can cite: carbon nanotubes-adsorbed electrospun PA66 nanofiber bundles with improved conductivity and robust flexibility [25], lightweight conductive graphene/thermoplastic polyurethane foams with ultrahigh compressibility for piezoresistive sensing [26], electrically conductive strain sensing polyurethane nanocomposites with synergistic carbon nanotubes and graphene bifillers [27].

The distinction between SPEs and GPEs is artificial, because the "plasticizers" used in the latter are sometimes either polymers or oligomers with molecular weights near the threshold $\left(M_{\mathrm{w}} \sim 5000\right)$ of polymers.

\subsection{Solid polymer electrolytes}

Almost all the effort on SPEs have been focused on the polyether structure, with the $\left(-\mathrm{CH}_{2}-\mathrm{CH}_{2}-\mathrm{O}^{-}\right)_{\mathrm{n}}$ oligoether being the structural unit. In practice, poly(ethylene oxide) (PEO) was used because of its low glass transition temperature and its ability to dissolve Li salts. Unfortunately, the ionic conductivity must be much higher so that the charge rate is raised to a practical value, and also the transference number must be increased to reduce the formation of concentration gradients in the electrolyte [24,28].

The low conductivity of PEO electrolytes is mainly due to its partial crystallization until $60{ }^{\circ} \mathrm{C}$, which reduces chain mobility. Different approaches were considered to overcome this problem. The introduction of grafted co-polymers hinders crystallization of the polyether chains and preserves the mechanical properties. A conductivity of $10^{-4} \mathrm{~S} \mathrm{~cm}^{-1}$ at room temperature was achieved with a grafted co-polymer of poly-(methoxy/hexadeca-poly(ethylene glycol) 
methacrylate) [29]. Another solution is to disperse ceramics, layered clays and other mesoporous particles in the polymer matrix (for a recent review of the effect of nanoparticles on electrolytes and electrolyte interface, see Ref. [30]). The inorganic particles act as surface "plasticisers" that reduce the crystalline fraction in the polymer. The amorphization also generates more conductive pathways to increase ionic conductivity. In addition, the inorganic fillers act as Lewis acid-based centers that promote salt dissociation, thus freeing more $\mathrm{Li}^{+}$ions to increase the transference number. For instance, when a PEO-based electrolyte such as $\mathrm{PEO}_{8}-\mathrm{LiClO}_{4}(8: 1)$ is heated to above $60{ }^{\circ} \mathrm{C}$, it becomes amorphous, but the transition is reversible, i.e. it recrystallizes upon cooling back to room temperature. However, $\mathrm{TiO}_{2}$ or $\mathrm{Al}_{2} \mathrm{O}_{3}$ additives prevent the polymer chains from recrystallizing upon cooling, and the material remains amorphous. As a result, the ionic conductivity increased from $5 \times 10^{-8}$ to $10^{-5} \mathrm{~S} \mathrm{~cm}^{-1}$, and the transference number increased to 0.5 0.6 (see Figure 3) [31]. The increase of the lithium transference number is attributed to the Lewis acid property of the ceramic, which competes with $\mathrm{Li}^{+}$in forming complexes with the polymer chains in addition to hindering the ability of the polymer to crystallize. The transference number increased to 0.8 when 10 wt.\% $\mathrm{S}-\mathrm{ZrO}_{2}$ was added to $\mathrm{PEO}_{20}-\mathrm{LiBF}_{4}$ because the nano-sized sulfated zirconia has a much higher degree of acidity (100\% higher than sulphuric acid) [32]. The

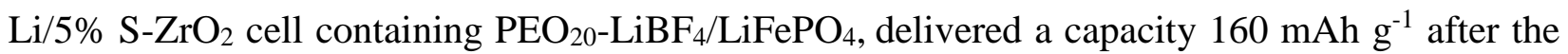
first cycle, and $140 \mathrm{mAh} \mathrm{g}^{-1}$ after 150 cycles at rate $\mathrm{C} / 5$ (current density $0.20 \mathrm{~mA} \mathrm{~cm}{ }^{-2}$ ) and 90 ${ }^{\circ} \mathrm{C}$, compared to $80 \mathrm{mAh} \mathrm{g}^{-1}$ after 150 cycles at $\mathrm{C} / 7$ rate at the same temperature in the absence of $\mathrm{S}_{-\mathrm{ZrO}}$. Similarly, 3 wt.\% silica aerogel powder (SAP) in polyacrylonitrile (PAN)-LiClO 4 used as the electrolyte in a $\mathrm{Li}$-metal//LiFePO 4 cell raised the capacity to $120 \mathrm{mAh} \mathrm{g}^{-1}$ over 20 cycles at $0.5 \mathrm{C}$ rate [33]. Borate-based anion receptors used with PEO-based electrolytes, either as additives or bonded covalently to the polymer chains, have successfully increased both the ion conductivity and the transference number, owing to the Lewis acidity of the boron center [34]. 
Another approach is to incorporate non-covalent bonds to prevent crystallization [35-37]. In particular, electrostatic interactions between $\mathrm{PEO}^{+}$and $\mathrm{PEO}^{-}$charged ionomers were effective to improve the mechanical strength and maintain the amorphous state [36].

In addition to PEO and its derivatives, other polymer structures have been proposed. In particular, a cross-linked polyphosphazene-based electrolyte with pendant ether chains mixed lithium bis(trifluoromethanesulfonyl)imide (LiTFSI) and lithium bis(oxalatoborate) (LiBOB) salt achieves a good conductivity at room temperature and stability versus $\mathrm{Li}$ metal. However, the $\mathrm{Li}^{+}$ transference number is too low, preventing its use as a practical electrolyte [38].

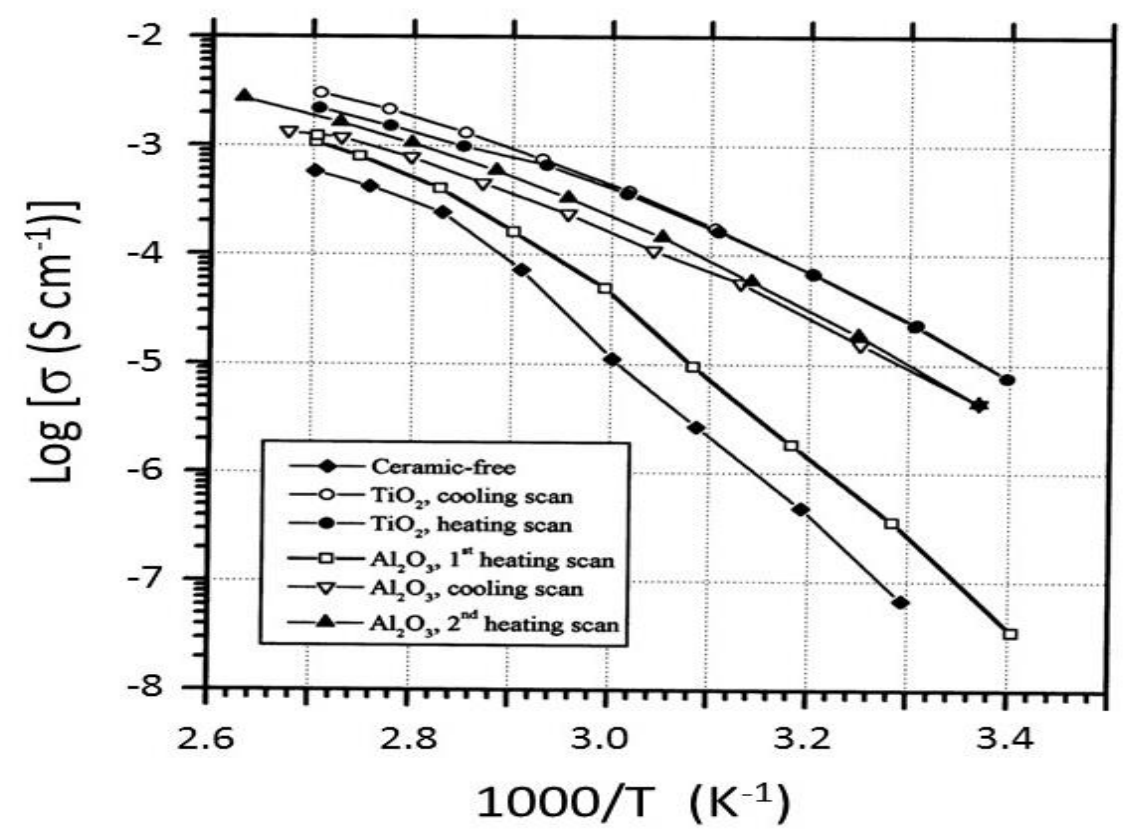

Figure 3. Arrhenius plots of the conductivity of the nanocomposite $\mathrm{PEO}_{8} \mathrm{LiClO}_{4}-10$ wt. $\% \mathrm{TiO}_{2}$, $\mathrm{PEO}_{8} \mathrm{LiClO}_{4}-10$ wt. $\% \mathrm{Al}_{2} \mathrm{O}_{3}$. The plot of a ceramic-free $\mathrm{PEO}_{8} \mathrm{LiClO}_{4}$ polymer electrolyte is illustrated for comparison purposes [31]. (Reproduced with permission from Elsevier).

\subsection{Glass-ceramic electrolytes}


Another problem with oligoether-based SPEs is the electrochemical stability window - the breakdown potential for ether linkages is below $4 \mathrm{~V}$. With such polymers, the cathode must then be limited to materials such as $\mathrm{LiFePO}_{4}$ and $\mathrm{V}_{2} \mathrm{O}_{5}$ for which the working potential is lower than $4 \mathrm{~V}$. At present, the best water-stable lithium-ion conducting solid electrolyte is $\mathrm{Li}_{1+x+y}\left(\mathrm{Ti}_{2} \mathrm{Ge}\right)_{1-x} \mathrm{Al}_{x} \mathrm{P}_{3-y} \mathrm{Si}_{\mathrm{y}} \mathrm{O}_{12}$ (LTAP), which exhibits a lithium-ion conductivity higher than $10^{-4}$ S.cm ${ }^{-1}$ at ambient temperature, and is stable in saturated $\mathrm{LiOH}$ and $\mathrm{LiCl}$ aqueous solution. This solid electrolyte is proposed for protected anode Li-air batteries [39]. However, it exhibits poor chemical stability towards lithium metal [40]. On the other hand, sulfide glass-ceramic electrolytes $\mathrm{Li}_{2} \mathrm{~S}-\mathrm{P}_{2} \mathrm{~S}_{5}$ are apparently inert towards lithium metal (with a SEI), and have advantages of high conductivity $\left(10^{-2} \mathrm{~S} \mathrm{~cm}^{-1}\right.$ at $25{ }^{\circ} \mathrm{C}$ for $\left.\mathrm{Li}_{7} \mathrm{~S}_{3} \mathrm{P}_{11}\right)$, wide electrochemical window, high lithium-ion transference number close to unity, and appropriate mechanical properties from simple pressing [41]. A conductivity $1.710^{-2} \mathrm{~S} \mathrm{~cm}^{-1}$ was achieved after heat treatment that reduced the grain-boundary resistance [42]. In addition, the Young's modulus of $\mathrm{Li}_{2} \mathrm{~S}-\mathrm{P}_{2} \mathrm{~S}_{5}$ sulfide-glass electrolytes reaches $20 \mathrm{Gpa}$ [43]. Such glass-ceramic electrolytes look very promising. They are also performing in all-solid-state Li-S batteries [41].

\subsection{Solid polymer and their composites with ionic liquids}

LiTFSI is the preferred Li salt for PEO-based polymers because the salt cations $\left(\mathrm{Li}^{+}\right.$ions) supply the electro-active species in the electrolyte, and TFSI anions exert a plasticizing effect on the polymer. The interface resistance between lithium metal and polymer electrolytes in a waterstable lithium electrode is the main contribution to the cell resistance and an important factor in initiating lithium dendrite formation [44-46]. Reduction of the interface resistance and increased transference number are observed by adding poly(ethylene glycol) dimethyl ether (PEGDME) to $\mathrm{PEO}_{18}$ LiTFSI [47], showing that PEGDME reduces the coordination of lithium ions with EO 
units by the high $M_{\mathrm{w}}$ PEO matrix. The net result is an enhanced mobility of $\mathrm{Li}^{+}$ions that enables them to decouple from the ion pairs. The molecular weight of PEGDME is usually 500, which illustrates that the use of low molecular weight oligomer ethers as a plasticizer was beneficial to enhance the transport properties of polymer electrolytes. The PEO ${ }_{18}$ LiTFSI-2PEGDME electrolyte exhibited a lithium-ion conductivity of $8.91 \times 10^{-4} \mathrm{~S} \mathrm{~cm}^{-1}$, a high diffusion coefficient of $3.37 \times 10^{-7} \mathrm{~cm}^{2} \mathrm{~s} \mathrm{~cm}^{-2}$ at $60{ }^{\circ} \mathrm{C}$, and a low interfacial resistance in contact with lithium metal [48] (see Figure 4). An electrolyte consisting of $\mathrm{PEGDME}$ and $\mathrm{LiCF}_{3} \mathrm{SO}_{3}$ salt in a lithium metal/polymer/LiFePO 4 cell delivered a stable capacity of $150 \mathrm{mAh} \mathrm{g}^{-1}$ [49].

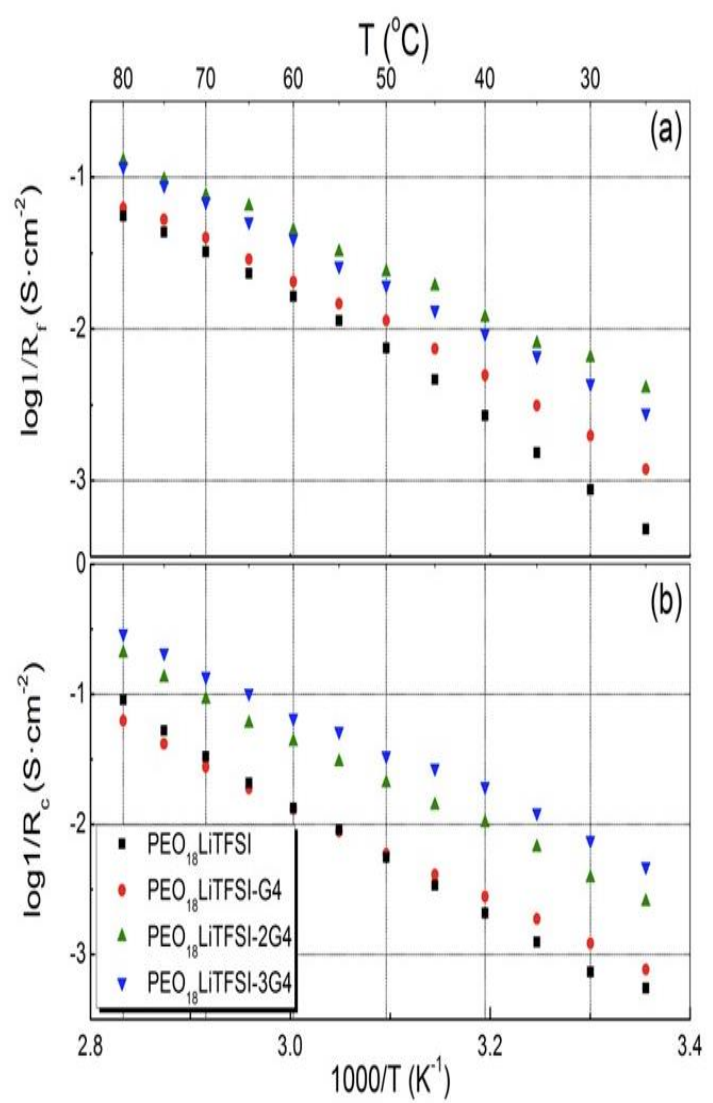

Figure 4. Temperature dependence of the resistance of a passivation film (SEI) formed on the lithium electrode surface by the reaction of lithium with the polymer electrolyte, and the charge transfer resistance for $\mathrm{Li} / \mathrm{PEO}_{18} \mathrm{LiTFSI}-x \mathrm{G} 4 / \mathrm{Li}[48]$, where G4 is tetraethylene glycol dimethyl 
ether. (Reproduced with permission from Elsevier).

A perspective article provides an overview of the developing energy related applications of ionic liquids (Ils) and offers some thoughts on the emerging challenges and opportunities. [50]. Addition of ionic liquids reduces the interface resistance and suppresses lithium dendrite formation. Such was the case for $\mathrm{PEO}_{18}$ LiTFSI [45]. N-alkyl-N-methyl-pyrrolidinium-based ionic liquids indicated high ionic conductivities, high lithium metal cycling efficiency and good performance in lithium metal polymer batteries [51], decreasing the operating temperature to 30$40{ }^{\circ} \mathrm{C}$ for low current applications [52]. Ternary mixtures of PEO, LiTFSI and $\mathrm{N}$-alkyl-N-methyl pyrrolidinium bis(trifluoromethanesulfonyl)imide (Pyr14TFSI) form electrolytes with high ionic conductivity even at room temperature, and show excellent performance for plating and stripping from lithium metal electrodes [53]. The study was extended to mixtures of PEO and LiTFSI with ionic liquids synthesized by combining different cations and fluorinated sulfonylimides [54]. Long-time stripping-plating $\left(0.1 \mathrm{~mA} \mathrm{~cm}{ }^{-1}\right.$ at $\left.40{ }^{\circ} \mathrm{C}\right)$ was feasible with cycling times ranging between 1400 and $3500 \mathrm{~h}$. The interfacial resistance in these ternary polymer electrolytes is at least one order of magnitude greater than the electrolyte resistance, confirming that it is the dominant part of the resistance. However the interfacial resistance decreases during the first few cycles, a general trend that is observed with polymer electrolytes, which is associated with a substantial reconstruction of the native SEI caused by the lithium deposition and plating [51]. With the ternary polymer electrolytes mentioned above, the initial resistance was recovered after around 800 cycles [54]. Ion conductivities higher than $10^{-3} \mathrm{~S} \mathrm{~cm}^{-1}$ at room temperature were achieved with sulfonium-based liquid crystals $[55,56]$. ILs containing high concentrations of lithium, up to $3.2 \mathrm{~mol} \mathrm{~kg}^{-1}$ in C3mpyr FSI, have excellent rate capability (higher than that of standard battery electrolytes) with lithium metal, owing to a large $\mathrm{Li}^{+}$transference number [57]. 
The dicyanamide (DCA) anion based ionic liquids offer exceptionally low viscosities and high conductivities, and are not expensive; using the non-fluorinated ionic liquid N-methyl-Nbutylpyrrolidinium dicyanamide to form non-volatile lithium battery electrolyte, good capacity retention for lithium metal and $\mathrm{LiFePO}_{4}$ and discharge capacities above $130 \mathrm{mAh} \mathrm{g}{ }^{-1}$ at $50{ }^{\circ} \mathrm{C}$ were obtained [58].

\subsection{Gel-polymer-based nanocomposites}

Gel polymers are a mixture of solid polymers and liquid electrolytes that are formulated with the goal to obtain the mechanical properties of the solid polymer while retaining the ionic conductivity of the liquid electrolyte. The progress on gel-type polymers before the year 2000 was reviewed in Ref. [59]. The more recent progress is essentially due to the efforts in nanosciences that allowed the synthesis of nano-composites.

$\mathrm{TiO}_{2}$ nanoparticles in poly(vinylidenefluoride-co-hexafluoropropylene) (PVdF-HFP) film reduced the crystallinity of the PVdF membrane and increased the ionic conductivity [60]. With 1 mol dm ${ }^{-3} \mathrm{LiClO}_{4} /$ ethylene carbonate $(\mathrm{EC})$ - dimethyl carbonate (DMC) (2:1) or $1 \mathrm{~mol} \mathrm{dm}^{-3}$ $\mathrm{LiPF}_{6} / \mathrm{EC}-\mathrm{DEC}(1: 1)$ as the electrolyte, the optimum $\mathrm{TiO}_{2}$ concentration was 20 wt.\% and 30 wt.\%, respectively, and the ionic conductivity increased to $3 \times 10^{-3} \mathrm{~S}_{\mathrm{cm}} \mathrm{cm}^{-1}$ and $1 \times 10^{-2} \mathrm{~S}_{\mathrm{cm}} \mathrm{cm}^{-1}$, respectively. These films were thus considered as suitable to rechargeable lithium batteries. An emphasis was also directed at decreasing the interfacial resistance between the polymer electrolyte and lithium-metal electrode. This was achieved by evaluating the role of the solidsolvent interaction of the nanoscale $\mathrm{TiO}_{2}$ filler. Adding 50 wt. $\% \mathrm{TiO}_{2}$ nanoparticles to a gel consisting of $\mathrm{LiClO}_{4}, \mathrm{EC}$, propylene carbonate (PC) and poly(methyl methacrylate) PMMA increased the transference number for $\mathrm{Li}^{+}$by $50 \%$ at $80{ }^{\circ} \mathrm{C}$ and improved the ionic conductivity [61], because the interaction between $\mathrm{TiO}_{2}$ and $\mathrm{Li}^{+}$ions break the ionic cross-linking between 
polymer chains originally formed by the $\mathrm{Li}^{+}$-polymer interaction.

$\mathrm{TiO}_{2}$ does not participate in the ionic transfer. However, other fillers are active and do participate in ion transfer, for example, clays. Suspending hectorite, which is the lithium salt of a macroanion, as a filler in 1:1 v/v mixture of EC in poly(ethylene glycol dimethyl) ether to form a gel resulted in a transference number to 1 . The ionic conductivity was about $10^{-4} \mathrm{~S} \cdot \mathrm{cm}^{-1}$ at room temperature and $10^{-3} \mathrm{~S} \mathrm{~cm}^{-1}$ at $70{ }^{\circ} \mathrm{C}$ [36] because the hectorite acts as the anion to allow $\mathrm{Li}^{+}$ transport. Deka et al. $[62,63]$ studied nanocomposite polymer electrolytes based on intercalation of PVdF polymer into the galleries of organically modified montmorillonite (MMT) clay. The nanocomposites were soaked with $1 \mathrm{~mol} \mathrm{dm}^{-3} \mathrm{LiClO}_{4}$ in a $1: 1(\mathrm{v} / \mathrm{v})$ solution of PC and diethyl carbonate (DEC) to obtain the required gel electrolytes. The ionic conductivity of the nanocomposite GPE attains a maximum value of $2.3 \times 10^{-3} \mathrm{~S} \cdot \mathrm{cm}^{-1}$ for a $4 \mathrm{wt} . \%$ clay loading at room temperature, and enhanced electrochemical and interfacial properties were obtained. Another active filler is $\mathrm{LiV}_{3} \mathrm{O}_{8}$ in $\mathrm{PMMA} / \mathrm{LiV}_{3} \mathrm{O}_{8}$ composite. PMMA alone is stable only for about 5 days, after which intercalation disrupts the porous structure. The $\mathrm{LiV}_{3} \mathrm{O}_{8}$ fillers improve the stability up to 10 days, and the conductivity is stabilized to $10^{-3} \mathrm{~S}_{\mathrm{cm}} \mathrm{cm}^{-1}$ with tests over 18 days [64]. The interlayer distance of $\mathrm{LiV}_{3} \mathrm{O}_{8}$ increases from 6.3 to $12.8 \AA$ upon introduction of PMMA, which proves the successful insertion of the PMMA chains between the layers [65]. The conductivity and interfacial stability of $\mathrm{PMMA} / \mathrm{LiV}_{3} \mathrm{O}_{8}$ saturated with $1 \mathrm{M} \mathrm{LiClO}_{4}-\mathrm{PC} / \mathrm{DEC}$ were determined. The ionic conductivity at room temperature was $1.8 \times 10^{-3} \mathrm{~S} \mathrm{~cm}^{-1}$. This was attributed to the high dielectric constant of the $\mathrm{V}_{3} \mathrm{O}_{8}{ }^{-}$layers, which enhances the dissolution of $\mathrm{LiClO}_{4}$ and the aggregation of the $\mathrm{PMMA} / \mathrm{LiV}_{3} \mathrm{O}_{8}$ particles, which results from the cross-linking of $\mathrm{LiV}_{3} \mathrm{O}_{8}$ $\mathrm{LiV}_{3} \mathrm{O}_{8}$ due to some polymer chains intercalated between $\mathrm{LiV}_{3} \mathrm{O}_{8}$ layers [65]. 


\subsection{Block copolymers}

The block copolymers are made of different polymer segments that are covalently bound. For this reason, their mechanical properties are enhanced compared to other polymer electrolytes mentioned in previous sections [66]. The combination polystyrene-PEO (PS-PEO), with a molar ratio $[\mathrm{Li}] /[\mathrm{EO}]=0.085[67]$, is the most attractive block-polymer electrolyte because these systems achieved an ionic conductivity of $10^{-3} \mathrm{~S} \mathrm{~cm}^{-1}$ and a shear modulus $10^{8} \mathrm{~Pa}$ at $90{ }^{\circ} \mathrm{C}$ [68].

A LiTFSI-doped poly(styrene- $b$-(styrene- $g$-ethylene oxide)- $b$-styrene) (a symmetric triblock copolymer electrolyte with $60 \mathrm{wt} . \%$ PEO) exhibited an elastic modulus of $10^{9} \mathrm{dyn} \mathrm{cm}^{-2}$ between 0 and $100{ }^{\circ} \mathrm{C}$, much higher than the corresponding elastic modulus of PEO homopolymer electrolytes [69]. This elastic modulus is close to the shear modulus required (5-7 GPa) to inhibit macroscopic dendrite formation (see section III-B). Additionally, the ionic conductivity of this graft copolymer electrolyte was $2 \times 10^{-5} \mathrm{~S} \mathrm{~cm}^{-1}$ at room temperature, but increased to $10^{-4} \mathrm{~S} \mathrm{~cm}^{-1}$ at $60^{\circ} \mathrm{C}$.

Young et al. [70] proposed a mixed-salt to suppress the crystalline phase in the PSPEO:LiTFSI:LiClO 4 system ([EO]:[Li] = 6:1). They observed a significant increase in the room temperature ionic conductivity compared to single-salt PS-PEO, which opens the route for further studies of mixed-salt systems to obtain new electrolytes for lithium batteries.

Poly(styrene trifluoromethanesulfonylimide of lithium) (PSTFSILi)-b-PEO-b-PSTFSILi, where the $-\mathrm{SO}_{2} \mathrm{~N}(\mathrm{Li}) \mathrm{SO}_{2} \mathrm{CF}_{3}$ anionic group is attached to the styrene nucleus, has a ionic conductivity of $1.3 \times 10^{-5} \mathrm{~S} \mathrm{~cm}^{-1}$ at $60{ }^{\circ} \mathrm{C}$ in single-ion polymer electrolyte systems, a high transference number $(>0.85)$, and improved mechanical strength and electrochemical stability compared with the corresponding PS-PEO-PS:LiTFSI materials [71]. This result illustrated in Figure 5 shows that a single-ion conductive electrolyte is also an option for improving the performance of lithium batteries. A capacity of more than $85 \%$ at a C/2 rate between 60 and 80 
${ }^{\circ} \mathrm{C}$ was obtained.

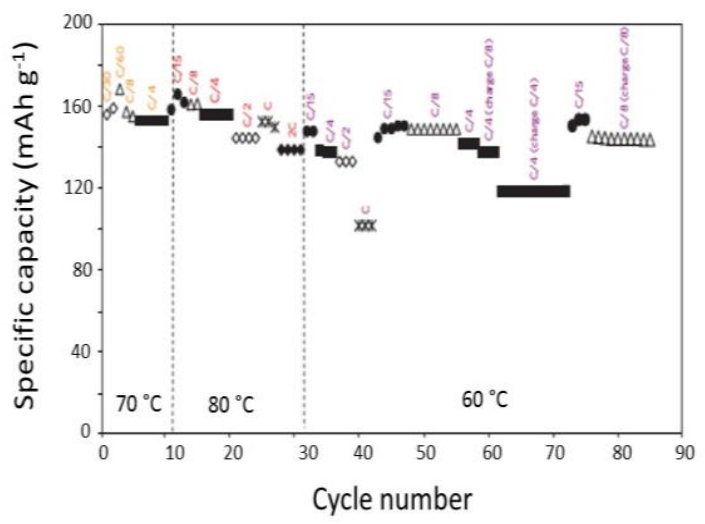

Figure 5. Cycle-life of Li/anionic block copolymer electrolytes in $(\mathrm{A}-\mathrm{BCE}) / \mathrm{LiFePO}{ }_{4}$ cell [71]. The different temperatures $\left(60,70\right.$ and $\left.80{ }^{\circ} \mathrm{C}\right)$ are noted in the figure, together with the different power rates where the rate is denoted $\mathrm{C} / \mathrm{n}$ where $\mathrm{C}$ is the theoretical cathode capacity and a full discharge occurs in $n$ hours. (Reproduced with permission from Nature).

The nature and concentration of the salt dopant is a parameter that affects the orderdisorder temperature and thus influences the ionic conductivity. This property was attributed to an increase in the effect Huggins interaction parameter $\chi_{\text {eff }}$ as a function of the salt concentration, and this parameter was used to estimate the effects of salt-doping. A review of the salt-doping and $\chi_{\text {eff }}$ on a variety of PEO-based block copolymers was presented elsewhere [66]. For PEO-PS,

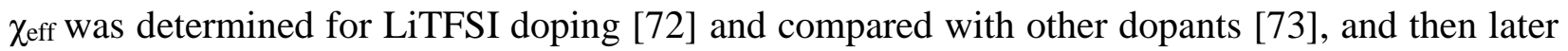
modeled in Ref. [74]. Polymer electrolytes with lithium salts derived from stronger acids exhibited higher conductivities. Another way to influence $\chi_{\text {eff }}$ is to manipulate the interfacial composition of the block-copolymers $[75,76]$.

In homopolymer electrolyte systems, the molecular weight has no significant effect on ionic conductivity above a critical molecular weight (3200 $\mathrm{g} \mathrm{mol}^{-1}$ ) of Rouse entanglement (the 
effect of molecular weight on cation mobility in polymer electrolytes [77]. To the contrary, in block-copolymer electrolyte systems, the conductivity of LiTFSI-doped PS-PEO increases as a function of the molecular weight of the PEO block, $M_{\mathrm{PEO}}$, when $M_{\mathrm{PEO}}>10,000 \mathrm{~g} \mathrm{~mol}^{-1}$ due to chain stretching $[67,68]$. However, the conductivity is a decreasing function at smaller $\mathrm{M}_{\mathrm{PEO}}$ because all ions are in contact with both the PS and PEO domains [78]. Therefore, highermolecular-weight block copolymers have higher ionic conductivity and mechanical strength. Unfortunately, the increased molecular weight also decreases their processability.

Finally, the microstructural tortuosity of the block-copolymers is reduced by magnetic field alignment [79-83], but other techniques [84-85] can improve the ionic conductivity by one order of magnitude.

While polyethers are the workhorse of solvating polymers with their ability to wrap around the $\mathrm{Li}^{+}$cation, recently, polyesters have shown some high conductivity with a salt, in the absence of any other additive. Examples include poly(alkylene carbonate)/Li[( $\left.\left.\mathrm{FSO}_{2}\right)_{2} \mathrm{~N}\right](\mathrm{LiFSI})$ and copolymers of trimethylene carbonate and $\varepsilon$-caprolactone/TFSI. With the latter polymers, it was possible to operate a Li/LFP battery close to ambient temperature [86].

\subsection{Ionic liquid -based and polymeric ionic liquid electrolytes}

Ionic liquids are non-volatile, have a wide electrochemical stability window and good ionic conductivity, but the $\mathrm{Li}^{+}$transport number of the corresponding electrolytes is lower than liquid organic electrolytes due to the high concentration of charge carriers other than Li. Good results can be obtained as a compromise, by mixing both ionic liquids and organic electrolyte solutions. This was investigated in GPEs that incorporate an organic electrolyte solution in a polymer matrix with a trapping structure enhanced by carbonate esters. One polymer commonly used in GPEs is polyvinylidene fluoride (PVdF), containing -C-F polar groups. The addition of ionic 
liquids in an organic electrolyte solution can increase the ionic conductivity and stabilize the lithium ions on the surface of PVdF-based membrane [87] A conductivity of $10^{-3} \mathrm{~S} \mathrm{~cm}^{-1}$ at room temperature was obtained by impregnating a mixture of LiTFSI, N-N-butyl-N-ethylpyrrolidinium N,N-bis(trifluorome-thanesulfonyl)imide (PYR 24 TFSI), and organic carbonates in a P(VDF-HFP) matrix [88]. Joost et al. [89] studied the structural properties and the electrochemical performance of an electrolyte based on PEO/N-methyl-N-butylpyrrolidinium bis(trifluoromethanesulfonyl)imide (PYR ${ }_{14}$ TFSI)/ LiTFSI, and observed complete amorphization of the PEO and decreased interaction between $\mathrm{Li}^{+}$and the oxygen atoms in the polyether.

Polymeric ionic liquids (PILs) are also frequently used in such electrolytes. PILs refer to a subclass of polyelectrolytes that feature an ionic liquid species in each monomer repeating unit, connected through a polymeric backbone to form a macromolecular architecture. They exhibit interesting performance such as film forming ability and good electrochemical properties. They also show excellent performance as polymer hosts for GPEs containing ionic liquids and lithium salts [90,91]. A review on these materials is found in Ref. [92]. A 40/50/10 PIL4/IL2/LiTFSI blend with PIL4 = Poly[1-(2-(2-(2-methoxyethoxy)ethoxy)ethyl)-1-methyl-pyrrolidinium] Bis(trifluoromethane)sulfonimide, IL2 = 1-(2-Methoxyethyl)-1-methylpyrrolidinium bis(trifluoromethane)sulfonimide performs better $\left(0.44 \mathrm{mS} \mathrm{cm}^{-1}\right.$ at $25^{\circ} \mathrm{C}$ and $3.3 \mathrm{mS} \mathrm{cm}^{-1}$ at $\left.100{ }^{\circ} \mathrm{C}\right)$ than ternary blends with similar weight ratios based on poly(diallyldimethylammonium) TFSI, PYR14TFSI and LiTFSI $\left(0.16 \mathrm{mS} \mathrm{cm}^{-1}\right.$ at $\left.20^{\circ} \mathrm{C}\right)$ and is similar to ternary systems prepared with PEO, PYR14TFSI and LiTFSI $\left(0.37 \mathrm{mS} \mathrm{cm}^{-1}\right.$ at $\left.20{ }^{\circ} \mathrm{C}\right)$. It also has a good interface stability against lithium metal [93]. This electrolyte in a $\mathrm{Li}^{2} \mathrm{LiFePO}_{4}$ cell at $40{ }^{\circ} \mathrm{C}$ delivered a discharge capacity of above $140 \mathrm{mAh} \mathrm{g}^{-1}$ at $\mathrm{C} / 5$, for 70 cycles. A series of alkylguanidinium-based PIL as electrolyte membrane obtained similar results [94,95]. An electrolyte with succinonitrile (NC$\mathrm{CH}_{2}-\mathrm{CH}_{2}-\mathrm{CN}, \mathrm{SN}$ ) matrix (a non-ionic plastic crystal acting as lithium ion transport channels) 
and a cross-linking composite framework composed of trimethylolpropane propoxylate triacrylate (TPPTA) and vinyl-functionalized $\mathrm{SiO}_{2}$ particles (providing a mechanical skeleton) exhibits excellent thermal stability up to $230{ }^{\circ} \mathrm{C}$, good interfacial compatibility with electrodes, and good ionic conductivity $7.02 \times 10^{-4} \mathrm{~S} \mathrm{~cm}^{-1}$ at $25{ }^{\circ} \mathrm{C}$ [96,97]. Another advantage of succinonitrile-based electrolytes is that the electrochemical window is large (up to $5 \mathrm{~V}$ ). $\mathrm{Li} / \mathrm{LiFePO}_{4}$ cells with such an electrolyte delivered a capacity of $150 \mathrm{mAh} \mathrm{g}^{-1}$ at $0.1 \mathrm{C}$ and $25^{\circ} \mathrm{C}$, with excellent rate capacity retention. The cells achieved stable discharge capacities of 131.8 and 121.2 $\mathrm{mAh} \mathrm{g}^{-1}$ at $0.5 \mathrm{C}$ and $1 \mathrm{C}$ rate, respectively, demonstrating that this electrolyte has potential for application in lithium batteries.

Promising results were also obtained by mixing block-copolymers and ionic liquids as new electrolytes. Elabd and Winey showed that the ionic conductivity is higher than the random copolymer and homopolymer analogs due to the effects of local confinement and connectivity of conducting ions in nanoscale block-copolymer domains [98,99].

\subsection{Plastic crystals}

Organic ionic plastic crystals (OIPCs) have a three-dimensional lattice, but with rotational motion of some fraction of the species possible that allows the materials to flow under stress. This plasticity reduces the poor contact between the electrodes and the electrolyte that can result from the volume changes during cycling. It also responds like solid electrolytes with a good ionic conductivity when doped with a lithium salt. Another review is found in Ref. [100]. By convention, the phase just below the melting point is denoted phase I. It is usually the most plastic and conductive phase. Unfortunately, many OIPCs are in this phase only above room temperature. However, tetraethylammonium dicyanamide ([Et4N][DCA]) is already in phase I at room temperature. This is also the case of the nonafluoro-1-butane sulfonate salts that exhibit 
excellent electrochemical and thermal stability. Doping OIPCs can also increase the ionic conductivity by orders of magnitude. Such is the case when LiI is added to dimethylpyrrolidium (Cnmpyr) salts. In addition, doping can also shift the transition to the most ordered phase to lower temperature. Such is the case when the plastic crystal $[\mathrm{C} 2 \mathrm{mpyr}]\left[\mathrm{BF}_{4}\right]$ is doped with supercritical $\mathrm{CO}_{2}$. LiTFSI-doped $\mathrm{C} 2 \mathrm{mpyr}$ electrolyte tested in lithium batteries supports currents approaching $0.5 \mathrm{~mA} \mathrm{~cm}^{-2}$ at $50{ }^{\circ} \mathrm{C}$ [101]. $\mathrm{Li}\left[\mathrm{CF}_{3} \mathrm{BF}_{3}\right]$-doped N,N-diethyl-N-methyl-N-(n-propyl)ammonium trifuoromethyltrifuoroborate $\left(\left[\mathrm{N}_{1223}\right]\left[\mathrm{CF}_{3} \mathrm{BF}_{3}\right]\right)$ has high conductivity at room temperature as well as sufficiently wide electrochemical window [102], which is promising for lithium batteries. Lithium-doped organic salts based on the perfluoroalkyltrifluoroborate anion are electrochemically stable, and exhibit phase I from 20 to $95^{\circ} \mathrm{C}$, conductivity from $10^{-4}-10^{-3} \mathrm{~S}$ $\mathrm{cm}^{-1}$ and an electrochemical window of approximately $5.5 \mathrm{~V}$ [103]. Other plastic crystal systems based on ammonium TFSI salts are also lithium-compatible electrolytes [104]. More recently, a solid electrolyte consisting of $4 \mathrm{~mol} \%$ LiFSI in P1444FSI proved to be very promising [105]. It has a large electrochemical window, high ionic conductivity $\left(2.6 \times 10^{-4} \mathrm{~S} \mathrm{~cm}^{-1}\right.$ at $\left.\mathrm{RT}\right)$ and the ability to form a stable and conductive SEI on the lithium metal surface. Tested in a cell with lithium metal and $\mathrm{LiFePO}_{4}$ electrodes, high capacity retention and rate capability were observed (see Figure 6). The stable SEI may be derived from the formation of a thin layer of chemically and/or morphologically 'altered' solid electrolyte in the vicinity of the metal surface; its formation is influenced by solid-state ion diffusion processes and mechanical stresses [106]. Moreover, the $[\mathrm{FSI}]$ anion forms a stable and conductive SEI with the consequence that it supports long-term cycling of the deposition/stripping process on lithium metal very well [107]. Owing to these combined effects, the cell delivered $160 \mathrm{mAh} \mathrm{g}^{-1}$ at $0.1 \mathrm{C}$ rate, close to the theoretical value, and still $118 \mathrm{mAh} \mathrm{g}^{-1}$ at $1 \mathrm{C}$ rate at room temperature. 


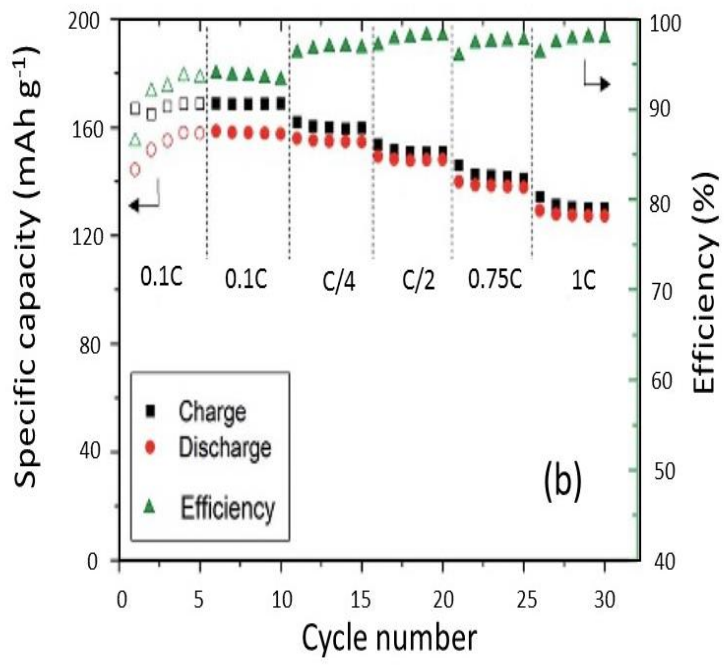

Figure 6. (a) Temperature dependence of the conductivity for LiFSI-doped P1444FSI. (b) Cell capacity retention of $\mathrm{Li}_{/} / \mathrm{LiFePO}_{4}$ using the composite electrolyte 4 mol.\% LiFSI doped P1444FSI and polyethylene separator. The initial 5 cycles labelled by hollow data points were considered as preconditioning cycles [105]. (Reproduced with permission from CSJ Journals).

\section{Concluding remarks}

For now over twenty years, Li-ion batteries with liquid electrolytes have dominated. There is now a growing demand to further increase the energy density by the use of lithium metal as a replacement of the graphite/copper current collector assembly. Li metal/polymer batteries are again an option for many applications, including electric cars, as made evident by the success of the 'Autolib' electric car-sharing program using a battery with $\mathrm{LiFePO}_{4}$. The energy density is at least on a par with higher voltage cathode containing unsustainable Co derivatives). This success is due to the intensive research that produced improvements in the two properties that are the weaknesses of Li/polymer batteries: the formation and growth of dendrites at the lithium surface and the low conductivity of the polymer. Recently, a lithium metal/solid-polymer + 
LiTFSI/LiFePO 4 cell had a capacity of $130 \mathrm{mAh} \mathrm{g}^{-1}$ (i.e. $80 \%$ of its initial capacity after 1400 cycles at rate $C / 3$ charge and discharge rate) providing a lithium metal polymer cell with high energy density, high loading and a stable SEI [11] (see Figure 7). This opens the possibility of new applications that were so far restricted to Li-ion batteries, and with the advantage of good thermal stability because flammable liquid organic electrolytes are eliminated and a smaller selfdischarge rate occurs. While polymers have an initial advantage to resist the growth of dendrites, some further improvements could be gained inspired by recent findings. An interesting strategy is the simple and economical micro-needle pre-treatment technique for Li metal foil [18] and awaiting test with polymer electrolytes. Block copolymer electrolytes were recently proposed to combine the two opposing properties (mechanical and conductivity) in the same material. The most common architectures are the $\mathrm{AB}$ diblock and $\mathrm{BAB}$ triblock copolymers, where $\mathrm{A}$ is the ionic conductor block and B is the block providing the mechanical strength. A multifunctional single-ion polymer electrolyte based on polyanionic block copolymers comprising polystyrene segments was tested [82]. It overcomes most of the above limitations, with a lithium-ion transport number close to unity, excellent mechanical properties and an electrochemical stability window spanning $5 \mathrm{~V}$ versus $\mathrm{Li}^{+} / \mathrm{Li}^{0}$. Additives, such as ceramics and clay nanofillers, are able to improve the electrode/electrolyte interfacial stability in some cases, and provide an enhanced lithium-ion transport number and ionic conductivity [32]. As we have discussed, ionic liquids can be impregnated into polymer matrices to reach ad hoc conductivities at lower temperatures $\left(40{ }^{\circ} \mathrm{C}\right)$ than what is allowed with solvent-free polymer electrolytes. Another strategy to improve the ionic conductivity is to resort to the new super delocalized salts ("super TFSI") in which the negative charge is spread over more atoms than in TFSI [108]. Polyesters may provide conductivities at least equal to that of poly(ethers) and are expected to withstand $\approx 4.5 \mathrm{~V}$ vs. $\mathrm{Li}^{+} / \mathrm{Li}^{0}$, i.e. opening the use of higher voltages batteries (e.g. $\left.\mathrm{Li}(\mathrm{Mn}, \mathrm{Fe}) \mathrm{PO}_{4}\right)$. These 
improvements and innovative approaches regarding both the control of the Li metal surface and the conductivity and mechanical strength of the polymer electrolytes will accelerate the development and commercialization of easily processed lithium batteries with high energy density and fast charge/discharge rates. On a more general basis, the research on nanocomposites underlying the progress on lithium batteries has potential applications in other domains such as sensors. Exemples include a unique timely moment for embedding intelligence in applications [109], multi-leap motion sensor based demonstration for robotic refine tabletop object manipulation task [110], a study on key technologies of unmanned driving [111]. The research in such fields will in turn be beneficial to the progress in the conception of lithium batteries. The future direction of rechargeable lithium batteries should consider the following characteristics. For the electrolyte, we suggest a room-temperature solid-state composition based on a mixture or multilayer of ionic liquid-polymer, ceramic-polymer or glass-polymer, with transport number (see Figure 6b), and high ionic conductivity lithium salt (with F or without F) is need to enhance the performance of the batteries. The future cathodes should use multi-electron inorganic or organic compounds or their mixture, however organic cathodes with both electronic and ionic conductivity will be considered for fast charge-discharge. In addition, the electrodes and electrolytes must be environmentally friendly. 


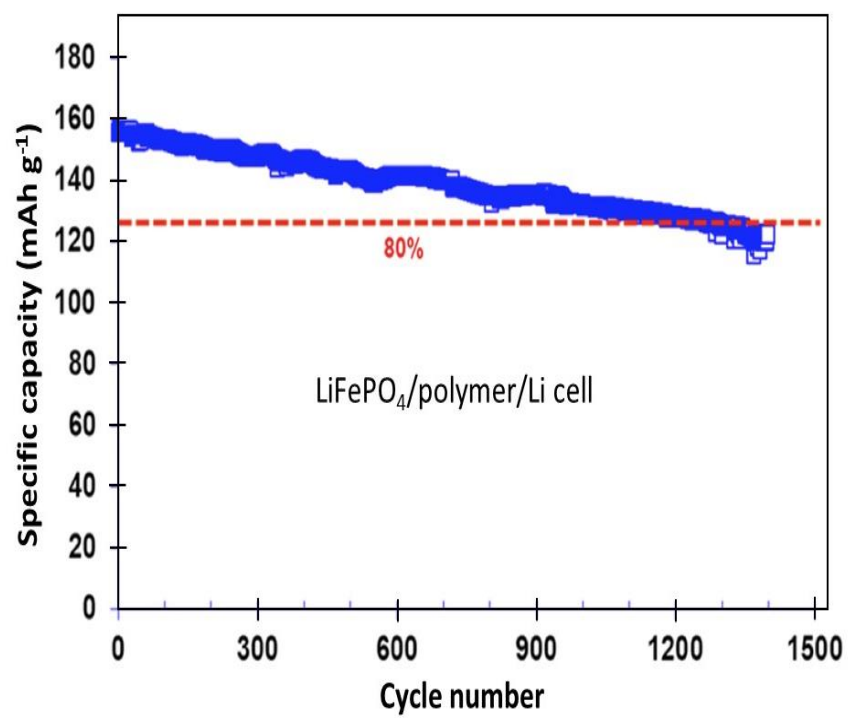

Figure 7. Cycle life of $\mathrm{Li} /$ polymer/LiFePO 4 cell [7] (cycles at $\mathrm{C} / 3$ charge and discharge rates, $1 \mathrm{~h}$ float). (Reproduced with permission from ACS Publications).

\section{References}

[1] M.B. Armand, J.M. Chabagno, M.J. Duclot, Poly-ethers as solid electrolytes. In Fast Transport in Solids, P. Vashishta, J.N. Mundy, G.K. Shenoy (Eds.) North-Holland: New York, 1979; pp 131-136.

[2] A. Hooper, J.M. North, The fabrication and performance of all solid state polymer-based rechargeable lithium cells. Solid State Ionics 9-10 (1983) 1161-1166.

[3] K. Zaghib, M. Dontigny, A. Guerfi, P. Charest, I. Rodrigues, A. Mauger, C.M. Julien, Safe and fast-charging Li-ion battery with long shelf life for power applications. J. Power Sources 196 (2011) 3949-3954.

[4] K. Zaghib, M. Dontigny, A. Guerfi, J. Trottier, J. Hamel-Paquet, V. Gariepy, K. Galoutov, P. Hovington, A Mauger, H. Groult, C.M. Julien, An improved high-power battery with increased thermal operating range: $\mathrm{C}-\mathrm{LiFePO}_{4} / / \mathrm{C}-\mathrm{Li}_{4} \mathrm{Ti}_{5} \mathrm{O}_{12}$. J. Power Sources 216 (2012) 
192-200.

[5] C.M. Julien, A. Mauger, A. Vijh, K. Zaghib, Lithium Batteries: Science and Technology. Springer: Heidelberg, 2016.

[6] H. Lyu, J. Liu, S. Qiu, Y. Cao, C. Hu, S. Guo, Z. Guo, Carbon composite spun fibers with in situ formed multicomponent nanoparticles for a lithium-ion battery anode with enhanced performance. J. Mater. Chem. A 4 (2016) 9881-9889.

[7] S. Qiu, G. Lu, J. Liu, H. Lyu, C. Hu, B. Li, X. Yan, Rechargeable $\mathrm{Co}_{3} \mathrm{O}_{4}$ porous nanoflake carbon nanotube nanocomposite lithium-ion battery anodes with enhanced energy performances. J. Guo, Z. Guo, RSC Adv. 5 (2015) 46509-46516.

[8] Y. Fu, H. Gu, X. Yan, J. Liu, Y. Wang, J. Huang, X. Li, H. Lv, X. Wang, J. Guo, G. Lu, S. Qiu, Z. Guo, Chromium(III) oxide carbon nanocomposites lithium-ion battery anodes with enhanced energy conversion performance. Chem. Engin. J. 277 (2015) 186-193.

[9] X. Su, Q. Wu, X. Zhan, J. Wu, S. Wei, Z. Guo, Advanced titania nanostructures and composites for lithium ion battery. J. Mater. Sci. 47 (2012) 2519-2534.

[10] D. Aurbach, E. Zinigrad, H. Teller, Y. Cohen, G. Salitra, H. Yamin, P. Dan, E. Elster, Attempts to improve the behavior of Li electrodes in rechargeable lithium batteries. $J$. Electrochem. Soc. 149 (2002) A1267-A1277.

[11] P. Hovington, M. Lagacé, A. Guerfi, P. Bouchard, A. Mauger, C.M. Julien, M. Armand, K. Zaghib, New Lithium metal polymer solid state battery for an ultrahigh energy: nano C$\mathrm{LiFePO}_{4}$ versus nano $\mathrm{Li}_{1.2} \mathrm{~V}_{3} \mathrm{O}_{8}$. Nano Lett. 15 (2015) 2671-2678.

[12] Z. Li, J. Huang, B.Y. Liaw, V. Metzler, J. Zhang, A review of lithium deposition in lithium-ion and lithium metal secondary batteries. J. Power Sources 254 (2014) 168-182.

[13] M.Z. Mayers, J.W. Kaminski, T.F. Miller, Suppression of dendrite formation via pulse 
charging in rechargeable lithium metal batteries. J. Phys. Chem. C 116 (2012) 2621426221.

[14] M.-H. Ryou, D.J. Lee, J.N. Lee, Y.M. Lee, J.K. Park, J.W. Choi, Excellent cycle life of lithium-metal anodes in lithium-ion batteries with mussel-inspired polydopamine-coated separators. Adv. Energy Mater. 2 (2012) 645-650.

[15] J.S. Kim, S.H. Baek, W.Y. Yoon, Electrochemical behavior of compacted lithium powder electrode in $\mathrm{Li} / \mathrm{V}_{2} \mathrm{O}_{5}$ rechargeable battery. J. Electrochem. Soc. 157 (2010) A984-A987.

[16] Y.S. Lee, J.H. Lee, J. Choi, W.Y. Yoon, D.W. Kim, Cycling characteristics of lithium powder polymer batteries assembled with composite gel polymer electrolytes and lithium powder anode. Adv. Funct. Mater. 23 (2013) 1019-1027.

[17] J. Heine, S. Krüger, C. Hartnig, U. Wietelmann, M. Winter, P. Bieker, Coated lithium powder (CLiP) electrodes for lithium-metal batteries. Adv. Energy Mater. 4 (2014) 1300815.

[18] M.H. Ryou, Y.M. Lee, Y. Lee, M. Winter, P. Bieker, Mechanical surface modification of lithium metal: Towards improved Li metal anode performance by directed Li plating. Adv. Func. Mater. 25 (2015) 834-841.

[19] R. Khurana, J.L. Schaefer, L.A. Archer, G.W. Coates, Suppression of lithium dendrite growth using cross-linked polyethylene/poly(ethylene oxide) electrolytes: A new approach for practical lithium-metal polymer batteries. J. Am. Chem. Soc. 136 (2014) 7395-7402.

[20] I. S. Kang, Y.-S. Lee, D.-W. Kim, Improved cycling stability of lithium electrodes in rechargeable lithium batteries. J. Electrochem. Soc. 161 (2014) A53-A57.

[21] M.H. Ryou, Y.M. Lee, J.K. Park, J.W. Choi, Mussel-inspired polydopamine-treated polyethylene separators for high-power Li-ion batteries. Adv. Mater. 23 (2011) 3066- 
3070.

[22] F. Ding, W. Xu, G.L. Graff, J. Zhang, M.L. Sushko, X. Chen, Y. Shao, M.H. Engelhard, Z. Nie, J. Xiao, X. Liu, P.V. Sushko, J. Liu, J.-G. Zhang, Dendrite-free lithium deposition via self-healing electrostatic shield mechanism. J. Am. Chem. Soc. 135 (2013) 44504456.

[23] G. Zheng, S.W. Lee, Z. Liang, H.-W. Lee, K. Yan, H. Yao, H. Wang, W. Li, S. Chu, Y. Cui, Interconnected hollow carbon nanospheres for stable lithium metal anodes. Nat. Nanotech. 9 (2014) 618-623.

[24] K. Matsumoto, T. Endo, Synthesis of networked polymers by copolymerization of monoepoxy-substituted lithium sulfonylimide and diepoxy-substituted poly(ethylene glycol), and their properties. J. Polym. Sci. Part A: Polym. Chem. 49 (2011) 1874-1880.

[25] X. Guan, G. Zheng, K. Dai, C. Liu, X. Yan, C. Shen, Z. Guo, Carbon Nanotubes-Adsorbed Electrospun PA66 Nanofiber Bundles with Improved Conductivity and Robust Flexibility. ACS Appl. Mater. \& Interfaces 8 (2016) 14150-14159.

[26] H. Liu, M. Dong, W. Huang, J. Gao, K. Dai, J. Guo, G. Zheng, C. Liu, C. Shen, Z. Guo, Lightweight conductive graphene/thermoplastic polyurethane foams with ultrahigh compressibility for piezoresistive sensing. J. Mater. Chem. C 5 (2017) 73-83.

[27] H. Liu, J. Gao, W. Huang, K. Dai, G. Zheng, C. Liu, C. Shen, X. Yan, J. Guo, Z. Guo, Electrically conductive strain sensing polyurethane nanocomposites with synergistic carbon nanotubes and graphene bifillers. Nanoscale 8 (2016) 12977-12989.

[28] R.L. Weber, Y. Ye, S.M. Banik, Y.A. Elabd, M.A. Hickner, M.K. Mahanthappa, Thermal and ion transport properties of hydrophilic and hydrophobic polymerized styrenic imidazolium ionic liquids. J. Polym. Sci. Part B: Polym. Phys. 49 (2011) 1287-1296.

[29] X. Zuo, X.-M. Liu, F. Cai, H. Yang, X.-D. Shen, G. Liu, A novel all-solid electrolyte based 
on a co-polymer of poly-(methoxy/hexadecal-poly(ethylene glycol) methacrylate) for lithium-ion cell. J. Mater. Chem. 22 (2012) 22265-22271.

[30] N. Salem, Y. Abu-Lebdeh, Effect of nanoparticles on electrolytes and electrode/electrolyte interface. In Nanotechnology for Lithium-Ion Batteries, Y. Abu-Lebdeh and I. Davidson (eds.) Springer: New York, 2013, pp 221-244.

[31] G.B. Appetecchi, F. Croce, L. Persi, F. Ronci, B. Scrosati, Transport and interfacial properties of composite polymer electrolytes. Electrochim. Acta 45 (2000) 1481-1490.

[32] F. Croce, L. Settimi and B. Scrosati, Superacid $\mathrm{ZrO}_{2}$-added, composite polymer electrolytes with improved transport properties Electrochem. Commun. 8 (2006) 364-368.

[33] Y.T. Chen, Y.C. Chuang, J.H. Su, H.C. Yu, Y.W. Chen-Yang, High discharge capacity solid composite polymer electrolyte lithium battery. J. Power Sources, 2011, 196, 28022809.

[34] M. Ciosek, M. Marcinek, G. Żukowska, W. Wieczorek, Lithium transference number measurements and complex abilities in anion trapping triphenyloborane-poly(ethylene oxide) dimethyl ether-lithium trifluoromethanesulfonate composite electrolyte. Electrochim. Acta 54 (2009) 4487-4493.

[35] J.L. Lutkenhaus and K. McEnnis, Hammond, P.T. Tuning the glass transition of and ion transport within hydrogen-bonded layer-by-layer assemblies. Macromolecules 40 (2007) 8367-8373.

[36] L. Zhang, B.L. Chaloux, T. Saito, M.A. Hickner, J.L. Lutkenhaus, Ion conduction in poly(ethylene oxide) ionically assembled complexes. Macromolecules 44 (2011) 97239730.

[37] L. Yao, J.J. Watkins, Photoinduced disorder in strongly segregated block copolymer composite films for hierarchical pattern formation. ACS Nano 7 (2013) 1513-1523. 
[38] S. Jankowsky, M.M. Hiller, H.D. Wiemhöfer, Preparation and electrochemical performance of polyphosphazene based salt-in-polymer electrolyte membranes for lithium ion batteries. J. Power Sources 253 (2014) 256-262.

[39] T. Zhang, N. Imanishi, S. Hasegawa, A. Hirano, J. Xie, Y. Takeda, O. Yamamoto, N. Sammes, Li/polymer electrolyte/water stable lithium-conducting glass ceramics composite for lithium-air secondary batteries with an aqueous electrolyte. J. Electrochem. Soc. 155 (2008) A965-A969.

[40] Y.S.Y. Shimonishi, T. Zhang, N. Imanishi, D. Im, D.J. Lee, A. Hirano, Y. Takeda, O. Yamamoto, N. Sammes, A study on lithium/air secondary batteries - Stability of the NASICON-type lithium-ion conducting solid electrolyte in alkaline aqueous solutions. $J$. Power Sources 196 (2011) 5128-5132.

[41] M. Tatsumisago, A. Hayashi, Sulfide glass-ceramic electrolytes for all-solid-state lithium and sodium batteries. Int. J. Appl. Glass Sci. 5 (2014) 226-235.

[42] Y. Seino, T. Ota, K. Takada, A. Hayashi, M. Tatsumisago, A sulphide lithium super ion conductor is superior to liquid ion conductors for use in rechargeable batteries. Energy Environ. Sci. 7 (2014) 627-631.

[43] A. Sakuda, A. Hayashi, M. Tatsumisago, Sulfide solid electrolyte with favorable property for all-solid-state lithium battery. Sci. Rep. 3 (2013) 2261.

[44] T. Zhang, N. Imanishi, Y. Shimonishi, A. Hirano, Y. Takeda, O. Yamamoto, N. Sammes, A novel high energy density rechargeable lithium/air battery. Chem. Commun. 46 (2010) $1661-1663$.

[45] S. Liu, H. Wang, N. Imanishi, T. Zhang, A. Hirano, Y. Takeda, O. Yamamoto, J. Yang, Effect of co-doping nano-silica filler and N-methyl-N-propylpiperidinium bis(trifluoromethenesulfonyl)imide into polymer electrolyte on Li dendrite formation in 
Li/poly(ethylene oxide)-Li(CF $\left.3 \mathrm{SO}_{2}\right)_{2} \mathrm{~N} / \mathrm{Li}$. J. Power Sources 196 (2011) 7681-7686.

[46] T. Zhang, N. Imanishi, A. Hirano, Y. Takeda, O. Yamamoto, Stability of Li/polymer electrolyte-ionic liquid composite/lithium conducting glass ceramics in an aqueous electrolyte. Electrochem. Solid-State Lett. 14 (2011) A45-A48.

[47] H. Wang, D. Im, D.J. Lee, M. Matsui, Y. Takeda, O. Yamamoto, N. Imanishi, A composite polymer electrolyte protect layer between lithium and water stable ceramics for aqueous lithium-air batteries. J. Electrochem. Soc. 160 (2013) A728-A733.

[48] H.M. Matsui, Y. Takeda, O. Yamamoto, D. Im, D. Lee, M. Imanishi, Interface properties between lithium metal and a composite polymer electrolyte of $\mathrm{PEO}_{18} \mathrm{Li}\left(\mathrm{CF}_{3} \mathrm{SO}_{2}\right)_{2} \mathrm{~N}-$ tetrazthylene glycol dimethyl ether. Membranes 3 (2013) 298-310.

[49] L. Carbone, M. Gobet, J. Peng, M. Devany, S. Scosati, S. Greenbaum, J. Hassoun, Polyethylene glycol dimethyl ether (PEGDME)-based electrolyte for lithium metal battery. J. Power Sources 299 (2015) 460-464.

[50] D.R. MacFarlane, N. Tachikawa, M. Forsyth, J.M. Pringle, P.C. Howlett, G.D. Elliott, J.H. Davis Jr., M. Watanabe, P. Simon, C.A. Angell, Energy applications of ionic liquids. Energy Environ. Sci.7(2014) 232-250.

[51] G.B. Appetecchi, G.T. Kim, M. Montanino, F. Alessandrini, S. Passerini, Room temperature lithium polymer batteries based on ionic liquids. J. Power Sources 196 (2011) 6703-6709.

[52] M. Wetjen, G.-T. Kim, M. Joost, M. Winter, S. Passerini, Temperature dependence of electrochemical properties of cross-linked poly(ethylene oxide)-lithium bis(trifluoromethanesulfonyl)imide- $N$-butyl- $N$-methylpyrrolidinium bis(trifluoromethanesulfonyl)imide solid polymer electrolytes for lithium batteries. Electrochim. Acta 87 (2013) 779-787. 
[53] M. Joost, M. Kunze, S. Jeong, M. Schönhoff, M. Winter, S. Passerini, Ionic mobility in ternary polymer electrolytes for lithium-ion batteries. Electrochim. Acta 86 (2012) 330338.

[54] H. De Vries, S. Jeong, S. Passerini, Ternary polymer electrolytes incorporating pyrrolidinium-imide ionic liquids. RSC Adv. 5 (2015) 13598-13606.

[55] A.S. Fisher, M.B. Khalid, M. Widstrom, P. Kofinas, Anion effects on solid polymer electrolytes containing sulfur based ionic liquid for lithium batteries. J. Electrochem. Soc. 159 (2012) A592-A597.

[56] A.S. Fisher, M.B. Khalid, P. Kofinas, Block copolymer electrolyte with sulfur based ionic liquid for lithium batteries. J. Electrochem. Soc. 159 (2012) A2124-A2129.

[57] H. Yoon, P.C. Howlett, A.S. Best, M. Forsyth, D.R. MacFarlane Fast charge/discharge of Li metal batteries using an ionic liquid electrolyte. J. Electrochem. Soc. 160 (2013) A1629-A1637.

[58] H. Yoon, G.H. Lane, Y. Shekibi, P.C. Howlett, M. Forsyth, A.S. Best, D.R. MacFarlane, Lithium electrochemistry and cycling behavior of ionic liquids using cyano based anions. Energy Environ. Sci. 6 (2013) 979-986.

[59] A.M. Stephan, Review on gel polymer electrolytes for lithium batteries. Euro. Polymer J. 42 (2006) 21-42.

[60] K.M. Kim, N.-G. Park, K.S. Ryu, S.H. Chang, Characterization of poly(vinylidenefluorideco-hexafluoropropylene)-based polymer electrolyte filled with $\mathrm{TiO}_{2}$ nanoparticles. Polymer 43 (2002) 3951-3957.

[61] J. Adebahr, A.S. Best, N. Byrne, P. Jacobsson, D.R. MacFarlane, M. Forsyth, Ion transport in polymer electrolytes containing nanoparticulate $\mathrm{TiO}_{2}$ : The influence of polymer morphology. Phys. Chem. Chem. Phys. 5 (2003) 720-725. 
[62] M. Deka, A. Kumar, Electrical and electrochemical studies of poly(vinylidene fluoride)clay nanocomposite gel polymer electrolytes for Li-ion batteries. J. Power Sources 196 (2011) 1358-1364.

[63] A.L. Sharma, A.K. Thakur, Polymer-ion-clay interaction based model for ion conduction in intercalation-type polymer nanocomposite. Ionics 16 (2010) 339-350.

[64] J.Y. Song, Y.Y. Wang, C.C. Wan, Review of gel-type polymer electrolytes for lithium-ion batteries. J. Power Sources 77(1999) 183-197.

[65] M. Duka, A. Kumar, Enhanced ionic conductivity in novel nanocomposite gel polymer electrolyte based on intercalation of PMMA into layered $\mathrm{LiV}_{3} \mathrm{O}_{8}$. J. Solid State Electrochem. 14 (2010) 1649-1656.

[66] W.-S. Young, W.-F. Kuan, T.H. Epps, Block copolymer electrolytes for rechargeable lithium batteries. J. Polymer Sci. B: Polymer Phys. 52 (2014) 1-16.

[67] A. Panday, S. Mullin, E.D. Gomez, N. Wanakule, V.L. Chen, A. Hexemer, J. Pople, N.P. Balsara, Effect of molecular weight and salt concentration on conductivity of block copolymer electrolytes. Macromolecules 42 (2009) 4632-4637.

[68] M. Singh, O. Odusanya, G.M. Wilmes, H.B. Eitouni, E.D. Gomez, A.J. Patel, V.L. Chen, M.J. Park, P. Fragouli, H. Iatrou, N. Hadjichristidis, D. Cookson, N.P. Balsara, Effect of molecular weight on the mechanical and electrical properties of block copolymer electrolytes. Macromolecules 40 (2007) 4578-4585.

[69] C. Wang, T. Sakai, O. Watanabe, K. Hirahara, T. Nakanishi, All solid-state lithiumpolymer battery using a self-cross-linking polymer electrolyte. J. Electrochem. Soc. 150 (2003) A1166-A1170.

[70] W.-S. Young, J.N.L. Albert, A.B. Schantz, T.H. Epps III, Mixed-salt effects on the ionic conductivity of lithium-doped PEO-containing block copolymers. Macromolecules 44 
(2011) 8116-8123.

[71] R. Bouchet, S. Maria, R. Meziane, A. Aboulaich, L. Lienafa, J.-P. Bonnet, T.N.T. Phan, D. Bertin, D. Gigmes, D. Devaux, R. Denoyel and M. Armand, Single-ion BAB triblock copolymers as highly efficient electrolytes for lithium-metal batteries. Nat. Mater. 12 (2013) 452-457.

[72] N.S. Wanakule, A. Panday, S.A. Mullin, E. Gann, A. Hexemer, N.P. Balsara, Ionic conductivity of block copolymer electrolytes in the vicinity of order-disorder and orderorder transitions. Macromolecules 42 (2009) 5642-5651.

[73] W.-S. Young, T.H. Epps III, Salt doping in PEO-containing block copolymers: counterion and concentration effects. Macromolecules 42 (2009) 2672-2678.

[74] N.S. Wanakule, J.M. Virgili, A.A. Teran, Z.-G. Wang, N.P. Balsara, Thermodynamic properties of block copolymer electrolytes containing imidazolium and lithium salts. Macromolecules 43 (2010) 8282-8289.

[75] B.S. Beckingham, R.A. Register, Synthesis and phase behavior of block-random copolymers of styrene and hydrogenated isoprene. Macromolecules 44 (2011) 43134319.

[76] B.S. Beckingham, R.A. Register, Regular mixing thermodynamics of hydrogenated styrene-isoprene block-random copolymers. Macromolecules 46 (2013) 3084-3091.

[77] J. Shi, C.A. Vincent, The effect of molecular weight on cation mobility in polymer electrolytes. Solid State Ionics 60 (1993) 11-17.

[78] R. Yuan, A.A. Teran, I. Gurevitch, S.A. Mullin, N.S. Wanakule, N.P. Balsara, Ionic conductivity of low molecular weight block copolymer electrolytes. Macromolecules 46 (2013) 914-921.

[79] P.W. Majewski, M. Gopinadhan, C.O. Osuji, Understanding anisotropic transport in self- 
assembled membranes and maximizing ionic conductivity by microstructure alignment. Soft Matter. 9 (2013) 7106-7116.

[80] P.W. Majewski, M. Gopinadhan, C.O. Osuji, Magnetic field alignment of block copolymers and polymer nanocomposites: Scalable microstructure control in functional soft materials. J. Polym. Sci. Part B: Polym. Phys. 50 (2012) 2-8.

[81] P.W. Majewski, M. Gopinadhan, W.-S. Jang, J.L. Lutkenhaus, C.O. Osuji, Anisotropic ionic conductivity in block copolymer membranes by magnetic field alignment. J. Am. Chem. Soc. 132 (2010) 17516-17522.

[82] H. Tran, M. Gopinadhan, P.W. Majewski, R. Shade, V. Steffes, C.O. Osuji, L.M. Campos, Monoliths of semiconducting block copolymers by magnetic alignment. ACS Nano 7 (2013) 5514-5521.

[83] M. Gopinadhan, P.W. Majewski, Y. Choo, C.O. Osuji, Order-disorder transition and alignment dynamics of a block copolymer under high magnetic fields by in situ X-ray scattering. Phys. Rev. Lett. 110 (2013) 078301.

[84] M.A. Torija, S.-H. Choi, T.P. Lodge, F.S. Bates, Large amplitude oscillatory shear of block copolymer spheres on a body-centered cubic lattice: Are micelles like metals? J. Phys. Chem. B 115 (2011) 5840-5848.

[85] I. Vukovic, H. Friedrich, D.H. Merino, G. Portale, G. Ten Brinke, K. Loos, Shear-induced orientation of gyroid PS-b-P4VP(PDP) supramolecules. Macromol. Rapid Commun. 34 (2013) 1208-1212.

[86] J. Mindemark, B., Sun, E. Törmä, D.Brandell, High-performance solid polymer electrolytes for lithium batteries operational at ambient temperature. J. Power Sources 298 (2015) 166-170.

[87] A. Fernicola, B. Scrosati, H. Ohno, Potentialities of ionic liquids as new electrolyte media 
in advanced electrochemical devices. Ionics 12 (2006) 95-102.

[88] M.A. Navarra, J. Manzi, L. Lombardo, S. Panero, B. Scrosati, Ionic liquid-based membranes as electrolytes for advanced lithium polymer batteries. ChemSusChem 4 (2011) 125-130.

[89] M. Joost, M. Kunze, S. Jeong, M. Schönhoff, M. Winter, S. Passerini, Ionic mobility in ternary polymer electrolytes for lithium-ion batteries. Electrochim. Acta 86 (2012) 330338.

[90] J. Yuan, D. Mecerreyes and M. Antonietti, Poly(ionic liquid)s: An update. Prog. Polymer Sci. 38 (2013) 1009-1036.

[91] G.B. Appetecchi, G.-T. Kim, M. Montanino, M. Carewska, R. Marcilla, D. Mecerreyes, I. De Meatza, Ternary polymer electrolytes containing pyrrolidium-based polymeric ionic liquids for lithium batteries. J. Power Sources 195 (2010) 3668-3675.

[92] M. Li, L. Yang, S. Fang, S. Dong, S. Hirano, K. Tachibana, Polymer electrolytes containing guanidinium-based polymeric ionic liquids for rechargeable lithium batteries. J. Power Sources 196 (2011) 8662-8668.

[93] M. Döbbelin, I. Azcune, M. Bedu, A. Ruiz de Luzuriaga, A. Genua, V. Jovanovski, G. Cabañero, V. Jovanovski, I. Odriozola, Synthesis of pyrrolidinium-based poly(ionic liquid) electrolytes with poly(ethylene glycol) side chains. Chem. Mater. 24 (2012) $1583-1590$.

[94] X. Li, Z. Zhang, S. Li, L. Yang, S.-I. Hirano, Polymeric ionic liquid-plastic crystal composite electrolytes for lithium ion batteries. J. Power Sources 307 (2016) 678-683.

[95] P.M. Simone, T.P. Lodge, Phase behavior and ionic conductivity of concentrated solutions of polystyrene-poly(ethylene oxide) diblock copolymers in an ionic liquid. ACS Appl. Mater. Interfaces 1 (2009) 2812-2820. 
[96] K. Liu, F. Ding, Q. Zhang, X. Liu, J. Zhang, Q. Xu, A cross-linking succinonitrile-based composite polymer electrolyte with uniformly dispersed vinyl-functionalized $\mathrm{SiO}_{2}$ particles for Li-ion batteries. ACS Appl. Mater. Interfaces 8 (2016) 23668-23675.

[97] L. Gwee, J.H. Choi, K.I. Winey, Y.A. Elabd, Block copolymer/ionic liquid films: The effect of ionic liquid composition on morphology and ion conduction. Polymer 51 (2010) $5516-5524$.

[98] Y. Ye, S. Sharick, E.M. Davis, K.I. Winey, Y.A. Elabd, High hydroxide conductivity in polymerized ionic liquid block copolymers. ACS Macro Lett. 2 (2013) 575-580.

[99] Y. Ye, J.-H. Choi, K.I. Winey, Y.A. Elabd, Polymerized ionic liquid block and random copolymers: effect of weak microphase separation on ion transport Macromolecules 45 (2012) 7027-7035.

[100] J. Pringle, P.C. Howlett, D.R. MacFarlane, M. Forsyth, Organic ionic plastic crystals: recent advances. J. Mat. Chem. 20 (2010) 2056-2062.

[101] P.C. Howlett, Y. Shekibi, D.R. MacFarlane, M. Forsyth, Li-metal symmetrical cell studies using ionic organic plastic crystal electrolyte. Adv. Eng. Mater. 11 (2009) 1044-1048.

[102] Z.-B. Zhou, H. Matsumoto, Lithium-doped, organic ionic plastic crystal electrolytes exhibiting high ambient-temperature conductivities. Electrochem. Commun. 9 (2007) $1017-1022$.

[103] Z.B. Zhou, H. Matsumoto, K. Tatsumi, Cyclic quaternary ammonium ionic liquids with perfluoroalbytrifluoroborates: Synthesis, characterization and properties. Chem.-Eur. J. 12 (2006) 2196-2212.

[104] Y. Abu-Lebdeh, E. Austin, I.J. Davidson, Spiro-ammonium imide salts as electrolytes for lithium batteries. Chem. Lett. 38 (2009)782-783.

[105] L. Jin, P.C. Howlett, J.M. Pringle, J. Janikowski, M. Armand, D.R. MacFarlane, M. 
Forsyth, An organic ionic plastic crystal electrolyte for rate capability and stability of ambient temperature lithium batteries. Energy Environ. Sci. 7 (2014) 3352-3361.

[106] L. Jin, P. Howlett, J. Efthimiadis, M. Kar, D. MacFarlane, M. Forsyth, Lithium doped $\mathrm{N}, \mathrm{N}$-dimethyl pyrrolidinium tetra fluoroborate organic ionic plastic crystal electrolytes for solid state lithium batteries. J. Mater. Chem. 21 (2011) 10171- 10178.

[107] A. Budi, A. Basile, G. Opletal, A.F. Hollenkamp, A.S. Best, R.J. Rees, A.I. Bhatt, A.P. O'Mullane, S.P. Russo, Study of the initial stage of solid electrolyte interphase formation upon chemical reaction of lithium metal and N-Methyl-N-propyl-pyrrolidiniumbis(fluorosulfonyl)imide. J. Phys. Chem. C 116 (2012) 19789-19797.

[108] Q. Ma, H. Zhang, C. Zhou, L. Zheng, P. Cheng, J. Nie, W. Feng, Y-S. Hu, H. Li, X. Huang, L. Chen, M. Armand, Z. Zhou Single lithium-ion conducting polymer electrolytes based on a super-delocalized polyanion. Angew. Chem. Int. Ed. 55 (2016) 2521-2525.

[109] C. Alippi, A unique timely moment for embedding intelligence in applications. CAAI Trans. Intelligence Technology 1 (2016) 1-3.

[110] H. Jin, Q. Chen, Z. Chen, Y. Hu, J. Zhang, Multi-leap motion sensor based demonstration for robotic refine tabletop object manipulation task. CAAI Trans. Intelligence Technology 1 (2016) 104-113.

[111] X. Zhang, H. Gao, M. Guo, G. Li, Y. Liu, D. Li, A study on key technologies of unmanned driving. CAAI Trans. Intelligence Technology 1 (2016) 4-13. 


\section{Figure captions}

Figure 1. Electrochemical measurements of $\mathrm{Li} / \mathrm{LiFePO}_{4}$ half-cells employing Li metal with and without micro-needle surface treatment. (a) A comparison of the discharge capacities of the cells at different discharge rates with the charge rate constant at $\mathrm{C} / 2\left(0.53 \mathrm{~mA} \mathrm{~cm}^{-2}\right)$. (b) The cycling performance was measured at $\mathrm{C} / 2$ rate $\left(0.53 \mathrm{~mA} \mathrm{~cm}{ }^{-2}\right)$ between 2.0 and $4.2 \mathrm{~V}\left(\mathrm{vs} \mathrm{Li}^{+} / \mathrm{Li}^{0}\right)$. The electrolyte is a mixture of ethylene carbonate/diethyl carbonate (EC:DEC $=1: 1$ by volume) containing $1 \mathrm{~mol} \mathrm{dm}^{-3} \mathrm{LiPF}_{6}$. [18]. (Reproduced with permission from ACS Publications).

Figure 2. Self-Healing Electrostatic Shield (SHES) mechanism at sequential steps [24]. (a): First, both $\left(\mathrm{Li}^{+}\right)$and the cations $\left(M^{+}\right)$are adsorbed on the $\mathrm{Li}$ surface under an applied voltage $(\mathrm{Va})$ slightly lower than the Li reduction potential but higher than the additive reduction potential. (b): Li forms protuberant tips. $\left(M^{+}\right)$with a reduction potential lower than $V a$ (c) will not electroplate on the tip. Instead, they will accumulate in the vicinity of the tip to form an electrostatic shield (d), which will repel incoming $\mathrm{Li}^{+}$ions, forcing further $\mathrm{Li}^{+}$deposition to adjacent regions of the anode (e) until a smooth deposition layer is formed (f). (Reproduced with permission from Elsevier).

Figure 3. Arrhenius plots of the conductivity of the nanocomposite $\mathrm{PEO}_{8} \mathrm{LiClO}_{4}-10$ wt.\% $\mathrm{TiO}_{2}$, $\mathrm{PEO}_{8} \mathrm{LiClO}_{4}-10$ wt. $\% \mathrm{Al}_{2} \mathrm{O}_{3}$. The plot of a ceramic-free $\mathrm{PEO}_{8} \mathrm{LiClO}_{4}$ polymer electrolyte is illustrated for comparison purposes [31]. (Reproduced with permission from Elsevier).

Figure 4. Temperature dependence of the resistance of a passivation film (SEI) formed on the 
lithium electrode surface by the reaction of lithium with the polymer electrolyte, and the charge transfer resistance for $\mathrm{Li} / \mathrm{PEO}_{18} \mathrm{LiTFSI}-x \mathrm{G} 4 / \mathrm{Li}$ [48], where G4 is tetraethylene glycol dimethyl ether. (Reproduced with permission from Elsevier).

Figure 5. Cycle-life of Li/anionic block copolymer electrolytes in (A-BCE)/LiFePO 4 cell [64]. The different temperatures $\left(60,70\right.$ and $\left.80{ }^{\circ} \mathrm{C}\right)$ are noted in the figure, together with the different power rates where the rate is denoted $\mathrm{C} / \mathrm{n}$ where $\mathrm{C}$ is the theoretical cathode capacity and a full discharge occurs in $n$ hours.

Figure 6. (a) Temperature dependence of the conductivity for LiFSI-doped P1444FSI. (b) Cell capacity retention of $\mathrm{Li} / / \mathrm{LiFePO}_{4}$ using the composite electrolyte 4 mol.\% LiFSI doped P1444FSI and polyethylene separator. The initial 5 cycles labelled by hollow data points were considered as preconditioning cycles [105]. (Reproduced with permission from CSJ Journals).

Figure 7. Cycle life of $\mathrm{Li} /$ polymer/LiFePO 4 cell [7] (cycles at $\mathrm{C} / 3$ charge and discharge rates, $1 \mathrm{~h}$ float). (Reproduced with permission from ACS Publications). 